\title{
Postnatal Inflammation Increases Seizure Susceptibility in Adult Rats
}

\author{
Michael A. Galic, ${ }^{1}$ Kiarash Riazi, ${ }^{2}$ James G. Heida, ${ }^{1}$ Abdeslam Mouihate, ${ }^{2}$ Neil M. Fournier, ${ }^{4}$ Sarah J. Spencer, ${ }^{2}$ \\ Lisa E. Kalynchuk, ${ }^{4}$ G. Campbell Teskey, ${ }^{3}$ and Quentin J. Pittman ${ }^{2}$ \\ Epilepsy and Brain Circuits Program, Hotchkiss Brain Institute, Departments of ${ }^{1}$ Neuroscience, ${ }^{2}$ Physiology and Biophysics, and ${ }^{3}$ Psychology, University of \\ Calgary, Calgary, Alberta, Canada T2N 4N1, and ${ }^{4}$ Neural Systems and Plasticity Research Group, Department of Psychology, University of Saskatchewan, \\ Saskatoon, Saskatchewan, Canada S7N 5A5
}

There are critical postnatal periods during which even subtle interventions can have long-lasting effects on adult physiology. We asked whether an immune challenge during early postnatal development can alter neuronal excitability and seizure susceptibility in adults. Postnatal day 14 (P14) male Sprague Dawley rats were injected with the bacterial endotoxin lipopolysaccharide (LPS), and control animals received sterile saline. Three weeks later, extracellular recordings from hippocampal slices revealed enhanced field EPSP slopes after Schaffer collateral stimulation and increased epileptiform burst-firing activity in CA1 after 4-aminopyridine application. Six to 8 weeks after postnatal LPS injection, seizure susceptibility was assessed in response to lithium-pilocarpine, kainic acid, and pentylenetetrazol. Rats treated with LPS showed significantly greater adult seizure susceptibility to all convulsants, as well as increased cytokine release and enhanced neuronal degeneration within the hippocampus after limbic seizures. These persistent increases in seizure susceptibility occurred only when LPS was given during a critical postnatal period (P7 and P14) and not before (P1) or after (P20). This early effect of LPS on adult seizures was blocked by concurrent intracerebroventricular administration of a tumor necrosis factor $\alpha$ (TNF $\alpha)$ antibody and mimicked by intracerebroventricular injection of rat recombinant TNF $\alpha$. Postnatal LPS injection did not result in permanent changes in microglial (Iba1) activity or hippocampal cytokine [IL-1 $\beta$ (interleukin- $1 \beta$ ) and TNF $\alpha$ ] levels, but caused a slight increase in astrocyte (GFAP) numbers. These novel results indicate that a single LPS injection during a critical postnatal period causes a longlasting increase in seizure susceptibility that is strongly dependent on TNF $\alpha$.

Key words: development; lipopolysaccharide; seizure; cytokine; tumor necrosis factor $\alpha$; interleukin- $1 \beta$

\section{Introduction}

Seizures in adults can be caused by any number of genetic factors or acquired clinical pathologies. However, in the face of such factors, there is substantial variation in both the likelihood that an individual will develop a seizure and in the severity of the condition. The relative contributions of genetic, environmental, and traumatic conditions to this diversity remain unknown. It has been postulated that early life events, for example a postnatal seizure brought about by whole-body hyperthermia, may predispose the brain to epilepsy later in life (Dubé et al., 2006).

Mounting evidence indicates that brief systemic inflamma-

\footnotetext{
Received Nov. 22, 2007; accepted May 19, 2008.

This work was supported by funding from the Canadian Institutes of Health Research (CIHR) (Q.J.P.) and by the Natural Sciences and Engineering Research Council of Canada (NSERC) (G.C.T., L.E.K.). L.E.K. holds a Canada Research Chair in Behavioural Neuroscience. M.A.G. is a Killam Scholar and was supported by scholarships from the Alberta Heritage Foundation for Medical Research (AHFMR), NSERC, and CIHR. N.M.F. was supported by scholarships from NSERC and the Savoy Foundation. K.R. was supported by a fellowship from AHFMR, and S.J.S. was supported by fellowships from AHFMR, AstraZeneca Canada, Inc., Heart and Stroke Foundation, and the Canadian Stroke Network. Q.J.P. is an AHFMR Medical Scientist. We thank Dr. B. Kuzmiski for comments on previous versions of this manuscript and Dr. M. Tsutsui for technical assistance.

Correspondence should be addressed to Michael A. Galic, Hotchkiss Brain Institute, Epilepsy and Brain Circuits Program, Department of Neuroscience, Faculty of Medicine, University of Calgary, Health Sciences Centre, 3330 Hospital Drive Northwest, Calgary, Alberta, Canada T2N 4N1. E-mail: magali@@ucalgary.ca.

DOI:10.1523/JNEUROSCI.1901-08.2008

Copyright $\odot 2008$ Society for Neuroscience $\quad$ 0270-6474/08/286904-10\$15.00/0
}

tion during critical periods of development, although not associated with obvious CNS injury, may result in long-lasting cerebral and peripheral vulnerability (programming or sensitization) well into adulthood (Eklind et al., 2005; Hagberg and Mallard, 2005; Godbout and Johnson, 2006). For example, adult rats that had been treated at postnatal day 14 (P14) with the immune activator lipopolysaccharide (LPS) showed increased brain NMDA receptor mRNA (Harré et al., 2008) and greater neuronal loss after global cerebral ischemia (Spencer et al., 2006a). Moreover, a similar postnatal treatment was also sufficient to evoke differences in pain sensitivity (Boissé et al., 2005), memory performance (Bilbo et al., 2005), and neuroimmune responses (Boissé et al., 2004) in adulthood. Consequently, it appears that the immature brain can be permanently modified after a single inflammatory episode in a manner that may contribute to a number of behavioral and physiological abnormalities.

The inflammatory response brought about by LPS is characterized by the generation of cytokines in the periphery and concomitant synthesis in the CNS (Layé et al., 1994; Nguyen et al., 1998; Verma et al., 2006). Among the proinflammatory cytokines produced in the brain are tumor necrosis factor $\alpha(\mathrm{TNF} \alpha)$ and interleukin-1 $\beta$ (IL-1 $\beta$ ) (Turrin et al., 2001), which are now accepted as bona fide modulators of both normal and abnormal 
neuronal transmission within the brain (Merrill, 1992; Mehler and Kessler, 1998; Vitkovic et al., 2000).

In the adult, clinical and experimental evidence suggests that infection or inflammation may be a potent contributor to seizure predisposition and occurrence, as well as seizure-related brain injury (Vezzani and Granata, 2005; Ravizza et al., 2006; Bartfai et al., 2007; Vezzani and Baram, 2007). Several reports have revealed that proinflammatory cytokines are involved in the pathophysiology of seizures and may be new targets for therapies against epilepsy (De Simoni et al., 2000; Virta et al., 2002; Turrin and Rivest, 2004; Dubé et al., 2005; Heida and Pittman, 2005; Bartfai et al., 2007; Somera-Molina et al., 2007). Because the early postnatal brain also generates cytokines in response to peripheral inflammation and seizures (Heida and Pittman, 2005; Ravizza et al., 2005), it is likely that the interaction of these cytokines with neuronal elements during development may alter the brain in a manner that makes it more susceptible to seizures as an adult. We therefore tested the hypothesis that postnatal inflammation may make adult animals more vulnerable to a challenge by convulsant drugs via an interaction with cytokines.

\section{Materials and Methods}

Animals and drugs. Timed pregnant Sprague Dawley rats were obtained from Charles River Laboratories and maintained in the Medical Sciences vivarium at the University of Calgary under standard specific pathogenfree (SPF) environmental conditions. They were housed at a constant temperature $\left(20-21^{\circ} \mathrm{C}\right)$ with food and water available ad libitum. The light/dark cycle was 12/12 h with photophase onset at 7:00 A.M. local time. Pregnant females were monitored for the parturition date that was taken as $\mathrm{P} 0$ at which time all litters were culled to 12 . After the postnatal treatments as described below, animals were returned to their dams, weaned at P21, and housed two per cage, where they were subjected to regular SPF husbandry until additional testing. All experiments involved male rats only to exclude any sex-specific interactions between treatments, and all rats were derived from multiple litters to preclude possible differences in individual maternal behaviors as a mitigating factor in any subsequent long-lasting changes induced in the offspring (Meaney and Szyf, 2005). All procedures were approved by the local Animal Care Committee and were compliant with the guidelines of the Canadian Council on Animal Care.

Kainic acid (KA) was obtained from A.G. Scientific, lithium and pilocarpine, pentylenetetrazol (PTZ), 4-aminopyridine (4-AP), and LPS were purchased from Sigma-Aldrich. The TNF $\alpha$ antibody Infliximab was obtained from Centocor, and the IL-1 receptor antagonist (IL-1ra) Anakinra was purchased from Amgen. Rat recombinant TNF $\alpha$ $(\operatorname{rrTNF} \alpha)$ was bought from PeproTech. All compounds were administered at $1 \mathrm{ml} / \mathrm{kg}$ unless otherwise stated.

Lipopolysaccharide injections. To determine whether a single inflammatory event during development can influence seizure susceptibility in later life, male rats were injected intraperitoneally on P14 with LPS (Escherichia coli, serotype $\mathrm{O} 26: \mathrm{B} 6 ; 25,100$, or $250 \mu \mathrm{g} / \mathrm{kg}$ ) or pyrogen-free saline. We previously established that $100 \mu \mathrm{g} / \mathrm{kg}$ LPS generates a mild inflammatory response in the host that lasts for $\sim 6-8 \mathrm{~h}$ (Heida et al., 2004; Ellis et al., 2006). Additional groups of rats were also injected on P14 with saline or LPS $(100 \mu \mathrm{g} / \mathrm{kg})$ to evaluate both the acute and chronic effects of LPS on cytokine and glial cell activity in the hippocampus (a seizure-vulnerable region). P14 is considered by some to be developmentally equivalent to a human infant of $\sim 1-2$ years of age (Gottlieb et al., 1977; Avishai-Eliner et al., 2002). To determine whether there was a critical age at which LPS could cause long-term changes to seizure susceptibility, rats were also treated with saline or LPS $(100 \mu \mathrm{g} / \mathrm{kg})$ at P1, P7, or P20.

In vitro hippocampal electrophysiology. Hippocampal slices $(n=43)$ were prepared from $\sim 5$-week-old male rats that had been treated with either saline or LPS $(100 \mu \mathrm{g} / \mathrm{kg})$ on P14. Under halothane anesthesia, brains were removed and placed in cold $\left(0-4^{\circ} \mathrm{C}\right)$ slicing solution (in mM): $87 \mathrm{NaCl}, 2.5 \mathrm{KCl}, 25 \mathrm{NaHCO}_{3}, 7 \mathrm{MgCl}_{2}, 1.25 \mathrm{NaH}_{2} \mathrm{PO}_{4}, 25$
D-glucose, 20 sucrose, and $0.48 \mathrm{CaCl}_{2}$ that was bubbled with $5 \% \mathrm{CO}_{2}$ / $95 \% \mathrm{O}_{2}$. Horizontal hippocampal slices $(400 \mu \mathrm{m})$ were cut using a vibratome and maintained for $45 \mathrm{~min}$ in a warm $\left(32^{\circ} \mathrm{C}\right)$ recovery solution composed of artificial CSF (aCSF) (in mM): $126 \mathrm{NaCl}, 2.5 \mathrm{KCl}, 1.2$ $\mathrm{NaH}_{2} \mathrm{PO}_{4}, 1.2 \mathrm{MgCl}_{2}, 2.4 \mathrm{CaCl}_{2}, 18 \mathrm{NaHCO}_{3}, 11 \mathrm{D}$-glucose, and 1.5 kynurenic acid, and continuously bubbled with $5 \% \mathrm{CO}_{2} / 95 \% \mathrm{O}_{2}$ to maintain a $\mathrm{pH}$ of 7.4. After $45 \mathrm{~min}$, slices were transferred into a second chamber that contained aCSF (but without kynurenic acid) for 3-4 h at room temperature. Slices were then transferred to a recording chamber that was continuously perfused with aCSF at $32^{\circ} \mathrm{C}$. Extracellular field potentials were recorded with glass micropipettes filled with aCSF (2-3 $\mathrm{M} \Omega$ ) and signals were acquired using an Axopatch 200B amplifier (Molecular Devices; low-pass filter, $5 \mathrm{kHz}$; high-pass filter, $1 \mathrm{~Hz}$; acquisition frequency, $10 \mathrm{kHz}$; gain, 500×). Evoked field EPSPs (fEPSPs) were elicited in the CA1 stratum radiatum region of the hippocampus by electrically stimulating the Schaffer collaterals (CA3) with a concentric bipolar electrode at $0,25,50,75$, and $100 \%$ maximal stimulation. The point at which the fEPSP slope did not increase further with increasing stimulation was taken as $100 \%$ maximal stimulation. To record spontaneous field activity, recording electrodes were placed in the CA1 stratum pyramidale. Spontaneous epileptiform activity (burst-firing) was induced by bath perfusion with aCSF containing $75 \mu \mathrm{M} 4$-AP, a potassium channel blocker (Perreault and Avoli, 1991; Yonekawa et al., 1995; Motamedi et al., 2006), for $30 \mathrm{~min}$. The epileptiform activity was quantified by determining the frequency of bursts during the last $10 \mathrm{~min}$ of 4-AP application, when burst-firing is stable and most robust (Salazar et al., 2003).

Lithium-pilocarpine seizure susceptibility. Six to 8 weeks after P14 injections of either 25,100 , or $250 \mu \mathrm{g} / \mathrm{kg}$ of LPS or saline, 37 rats received subcutaneous injections of lithium chloride $(3 \mathrm{mEq} / \mathrm{kg})$ followed $4 \mathrm{~h}$ later by pilocarpine $(30 \mathrm{mg} / \mathrm{kg}$ ) (LI-PILO). The latency to the first behavioral seizure after pilocarpine administration, referred to as the seizure onset time (SOT), was defined by the occurrence of forelimb clonus, rearing, and loss of balance, and was recorded to the nearest second for each animal by an individual blind to the postnatal treatment of the animal. Seizure onset time is a commonly used measure to describe seizure susceptibility to convulsant compounds in rats (Galic and Persinger, 2005; Lian et al., 2007). Electroencephalographic recordings at the time of overt convulsive behaviors have previously been shown to reveal clear, paroxysmal epileptiform discharges (Cavalheiro et al., 1987; Turski et al., 1989).

Pentylenetetrazol seizure susceptibility. To explore the developmental window in which LPS could produce changes in seizure onset, and to extend our findings to another chemoconvulsant with a different mechanism of action, we examined the seizure susceptibility of adult rats treated at either P1, P7, P14, or P20 with LPS $(100 \mu \mathrm{g} / \mathrm{kg})$ or saline $(n=$ 5-6/group) and given intravenous PTZ 6-8 weeks later. Jugular vein catheters were surgically implanted under ketamine/xylazine (85:15) anesthesia 3-4 d before seizure threshold testing with PTZ. This intravenous PTZ seizure protocol is considered an accurate way to assess seizure susceptibility (Ramzan and Levy, 1985; Mandhane et al., 2007). The clonic seizure threshold was determined by intravenous infusion of a $1 \%$ PTZ solution to the unrestrained rat through the catheter at a rate of 0.58 $\mathrm{ml} / \mathrm{min}$ using an infusion pump. The infusion was terminated when generalized (full-body) clonus was observed. The amount of PTZ (in milligrams per kilogram) required to induce a generalized clonic seizure was calculated and used as an index of seizure susceptibility.

Kainic acid seizure susceptibility and hippocampal cell degeneration. We further asked whether postnatal LPS treatment could generate a comparable susceptibility to a different chemoconvulsant that also causes a well defined pattern of neuronal damage in the hippocampus, yet through an entirely different mechanism of action as LI-PILO and PTZ. Male rats received either saline or LPS $(100 \mu \mathrm{g} / \mathrm{kg})$ on P14 as described above $(n=$ 6-7/group), and then 2 months later received $15 \mathrm{mg} / \mathrm{kg}$ KA intraperitoneally (Haas et al., 1996). Seizure onset time was recorded as defined above for LI-PILO, and pentobarbital (20 mg/kg, i.p.) was given $1 \mathrm{~h}$ later to suppress convulsions, promote survival, and importantly to equalize seizure duration. Rats were killed $24 \mathrm{~h}$ after SOT to determine the extent of neuronal degeneration using Fluoro-Jade histochemistry (Schmued et al., 1997). This time point is optimal for assessing the acute neuronal 
consequences (degeneration) of KA-induced seizures (Fujikawa et al., 2000).

Under pentobarbital anesthesia $(60 \mathrm{mg} / \mathrm{kg})$, rats were perfused with PBS followed by $4 \%$ neutral-buffered paraformaldehyde. The brains were placed into $10 \%$ neutral-buffered formalin for $48 \mathrm{~h}$ before processing. Brains were embedded in paraffin, and $10 \mu \mathrm{m}$ sections were cut through the hippocampus in the coronal plane and mounted on potassium dichromate gelatincoated slides. Fluoro-Jade histochemistry was conducted on alternating sections through the hippocampus from -3.30 to $-3.80 \mathrm{~mm}$ to bregma (Paxinos and Watson, 1998), which included the dentate gyrus (DG), CA3, and CA1 regions. Sections stained with Fluoro-Jade were then examined using an epifluorescent microscope with a fluorescein isothiocyanate filter at $100 \times$ magnification. Degenerating neurons fluoresced bright green, and the total number of neurons (pyramidal cells from the CA1 and CA3 regions and granule cells from the DG) from three sections was tabulated for the brain regions above and for each subject $(n=3-4$ / group) by an observer blind to the experimental treatments.

Cytokine assay and glial cell immunohistochemistry. To assess the acute effects of LPS on P14 rat microglia and cytokine (IL- $1 \beta$ and TNF $\alpha$ ) levels, we collected blood plasma at $2 \mathrm{~h}$ after injection, as well as hippocampal tissue 3 and $6 \mathrm{~h}$ after LPS $(100 \mu \mathrm{g} / \mathrm{kg})$ or saline injection ( $n=4-6$ /group). Previous reports show that cytokine expression is increased within the adult hippocampus $\sim 6 \mathrm{~h}$ after peripheral LPS (Nguyen et al., 1998; Turrin et al., 2001; Oprica et al., 2006).

We also collected hippocampal tissue from adult rats treated at P14 with saline or LPS (100 $\mu \mathrm{g} / \mathrm{kg}$ ) to examine whether any chronic or persistent differences exist in microglia or cytokine levels after postnatal injection. Moreover, we asked whether there were any differences in cytokine or microglia expression in the hippocampus $6 \mathrm{~h}$ after seizure induction in adult rats with a history of LPS exposure. Rats were seized with KA and treated with pentobarbital to abate seizure activity $1 \mathrm{~h}$ after seizure onset as above. We chose $6 \mathrm{~h}$ to assay for cytokines and microglia because this appears to be the peak time to inflammation in the hippocampus after seizures (Vezzani et al., 2002). Briefly, rats were deeply anesthetized with pentobarbital and perfused with PBS, brains were quickly removed, and the hippocampal tissue was rapidly dissected out. One hippocampus was snap frozen in liquid nitrogen and stored at $-80^{\circ} \mathrm{C}$ to be used for the cytokine assays, whereas the other was immersed in $10 \%$ neutral-buffered formalin and immunostained for quantification of microglia.

Measurements of the cytokines TNF $\alpha$ and IL- $1 \beta$ from the hippocampus of rats treated with saline or LPS was assessed using ELISA kits (BioSource). Interassay and intraassay variability (represented as coefficient of variation) for IL-1 $\beta$ were $8.7-9.7$ and $6.7-8.2 \%$, respectively, with a lower limit of detection at $<3 \mathrm{pg} / \mathrm{ml}$. Interassay and intraassay variability for TNF $\alpha$ were $3.5-4.3$ and $2.6-8.2 \%$, respectively, with a lower limit of detection at $<4 \mathrm{pg} / \mathrm{ml}$. All hippocampal samples were adjusted according to the protein content and presented as picograms per milligram.

For microglial measurements, the hippocampus was paraffin embedded and cut $(10 \mu \mathrm{m})$ in the coronal plane $[-3.30$ to $-3.80 \mathrm{~mm}$ to bregma (Paxinos and Watson, 1998)]. Sections were incubated with a primary Iba1 antibody (overnight; 1:500; rabbit; Wako Chemicals) followed by a secondary antibody [2 h; 1:1000; donkey anti-rabbit IgG (CY3); Jackson ImmunoResearch Laboratories]. The total number of microglia, as well
B

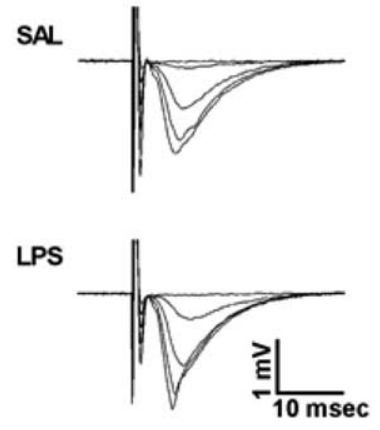

D

SAL

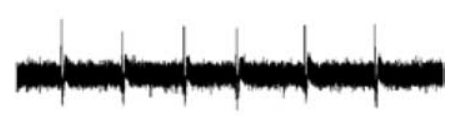

京

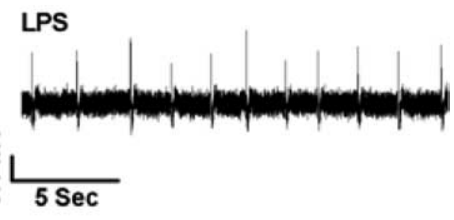

Figure 1. In vitro hippocampal slice electrophysiological recordings from 5-week-old rats treated postnatally with either SAL treated with either SAL or LPS at P14 showed significantly $(p<0.05)$ greater slopes (in microvolts per millisecond) at 75 and activity from the two treatment conditions. An asterisk denotes LPS-treated groups that differ significantly $(p<0.05)$ from

as the percentage of activated cells for each subject, was counted $(200 \times$ magnification) in the CA1 hippocampus as previously described (Spencer et al., 2007) by an examiner blind to the treatment history of the animals. We quantified microglial activation in CA1 because both the electrophysiology experiments and Fluoro-Jade histochemistry indicated robust effects within the CA1 region after LPS treatment. Activated microglia were defined as those with shorter less ramified processes, perikaryal hypertrophy, and ameboid appearance.

We also asked whether astrocyte numbers [identified by glial fibrillary acidic protein (GFAP) expression] were altered in adulthood after a P14 injection of LPS. Adult rats that received saline or LPS ( $n=4 /$ group) on P14 were given an overdose of pentobarbital and transcardially perfused with cold physiological saline followed by $10 \%$ neutral-buffered formalin. Brains were removed and postfixed for $72 \mathrm{~h}$ and sectioned in the coronal plane at $50 \mu \mathrm{m}$ on a vibrating microtome. Sections were stored in a cryoprotectant solution $[30 \%(\mathrm{w} / \mathrm{v})$ sucrose, $1 \%(\mathrm{w} / \mathrm{v})$ polyvinylpyrrolidone, $30 \%(\mathrm{v} / \mathrm{v})$ ethylene glycol] at $-25^{\circ} \mathrm{C}$ until processing.

Every sixth section through the entire hippocampal formation was processed using the free-floating method. Sections were incubated overnight at $4^{\circ} \mathrm{C}$ with a mouse monoclonal antibody raised against GFAP (1:3000; Sigma-Aldrich) followed by biotinylated horse anti-mouse IgG antibody (1:500; Vector Laboratories). Sections were placed in avidinbiotin-peroxidase complex (1:500; Vectastain Elite; Vector Laboratories) for $1 \mathrm{~h}$, and peroxidase activity was visualized using 3,3'diaminobenzidine and $\mathrm{H}_{2} \mathrm{O}_{2}$ in PBS. The specificity of the antibodies was determined by running the staining protocol in the absence of the primary antibodies. No staining was observed for any of these sections.

A single examiner who was blind to each animal's treatment performed the data collection. The total number of GFAP-positive cells in 
the left DG, CA3, and CA1 subfields of the hippocampal formation was estimated using the unbiased optical fractionator method (West et al., 1991), with assistance from a computerized stereology system (StereoInvestigator; MicroBrightField). All regions were traced at low power $(40 \times)$, demarcated using methodology previously used (Long et al., 1998; Grady et al., 2003), and counted at $400 \times$ magnification.

Intracerebroventricular injections. Cytokines are synthesized and released in the brain after a peripheral injection of LPS (Nguyen et al., 1998; Turrin et al., 2001). To evaluate the contribution of the central cytokine responses to peripheral LPS on the programming of the long-term effect on seizure susceptibility after peripheral LPS administration, 65 P14 rats were given intracerebroventricular injections of the natural antagonist for IL-1, IL-1ra (Anakinra; 10 or $50 \mu \mathrm{g} / 5 \mu \mathrm{l}$ ), or the TNF $\alpha$ neutralizing antibody (Infliximab; $50 \mu \mathrm{g} / 5 \mu \mathrm{l}$ ), concurrently with LPS $(100 \mu \mathrm{g} / \mathrm{kg}$, i.p.) or saline. We chose these dosages of IL-1 ra because previous reports indicate that $4 \mu \mathrm{g}$ intracerebroventricularly effectively antagonizes effects of peripheral pyrogens on rat behavior (Kent et al., 1992) and that 10 $\mu \mathrm{g}$ intracerebroventricularly significantly reduces the incidence of febrile seizures in rat pups (Heida and Pittman, 2005). In other P14 rats, $\operatorname{rrTNF} \alpha$ was administered intracerebroventricularly (bilaterally) at $1 \mu \mathrm{g} /$ $2.5 \mu \mathrm{l}$ per side to determine the role of this cytokine in promoting longterm seizure susceptibility ( $n=5-7 /$ group). Dosages of TNF $\alpha$ similar to this have been shown to influence neuronal transmission in the absence of negative side effects (Ignatowski et al., 1999; Reynolds et al., 2004). The surgical procedure, described in detail previously (Heida and Pittman, 2005), was performed under halothane anesthesia and required $<10 \mathrm{~min}$ to conduct. Animals were returned to their dams, and seizure thresholds were examined 6-8 weeks later using the PTZ paradigm described above.

Statistical analysis. All analyses were completed using Statistical Package for the Social Sciences software (SPSS, version 13). Between group differences in seizure susceptibility, cell counts, cytokine concentrations, and burst-firing frequency were analyzed using independent $t$ tests or a one-way ANOVA with Student-Newman-Keuls post hoc tests. The fEPSP slopes were examined using a two-way ANOVA followed by independent $t$ tests. Results are expressed as the mean $(\mathrm{M}) \pm \mathrm{SEM}$. The criterion for statistical significance was set at $p<0.05$.

\section{Results}

Enhanced hippocampal excitability and epileptiform activity after LPS

Electrophysiological recordings from hippocampal slices of $\sim 5$ week-old rats treated at P14 with saline or LPS revealed that the fEPSPs slopes recorded in the stratum radiatum of CA1 were significantly $\left(F_{(4,95)}=2.60 ; p<0.05\right)$ different between the postnatal treatments depending on stimulation intensity. Subsequent analyses determined that the major effects occurred at 75\% $(t=$ 2.16; $p<0.05)$ and $100 \%(t=2.38 ; p<0.05)$ maximum stimulation that displayed significant enhancement in the LPS-treated animals (Fig. 1 $A, B$ ). We also quantified the number of spontaneous epileptiform discharges from the stratum pyramidale layer of CA1 in response to $30 \mathrm{~min}$ bath application of 4-AP in rats treated with saline or LPS at P14. There was a significant difference in epileptiform discharge frequency between the two treatments $(t=3.05 ; p<0.05)$, such that rats given LPS postnatally showed consistently more burst-firing discharges than controls (Fig. 1C,D).

\section{Postnatal LPS increases adult seizure susceptibility to LI-PILO}

To determine whether postnatal LPS treatment altered adult seizure threshold, rats at 6-8 weeks of age were administered LIPILO. All rats developed the expected behavioral seizures that were similar between the different postnatal treatments. Rats given LPS $(100 \mu \mathrm{g} / \mathrm{kg})$ on P14, however, showed 30\% faster mean SOT (in minutes) compared with controls [saline (SAL) (M, 29.24; SEM, 2.58); LPS (M, 20.63; SEM, 1.20); $t=3.13 ; p<$
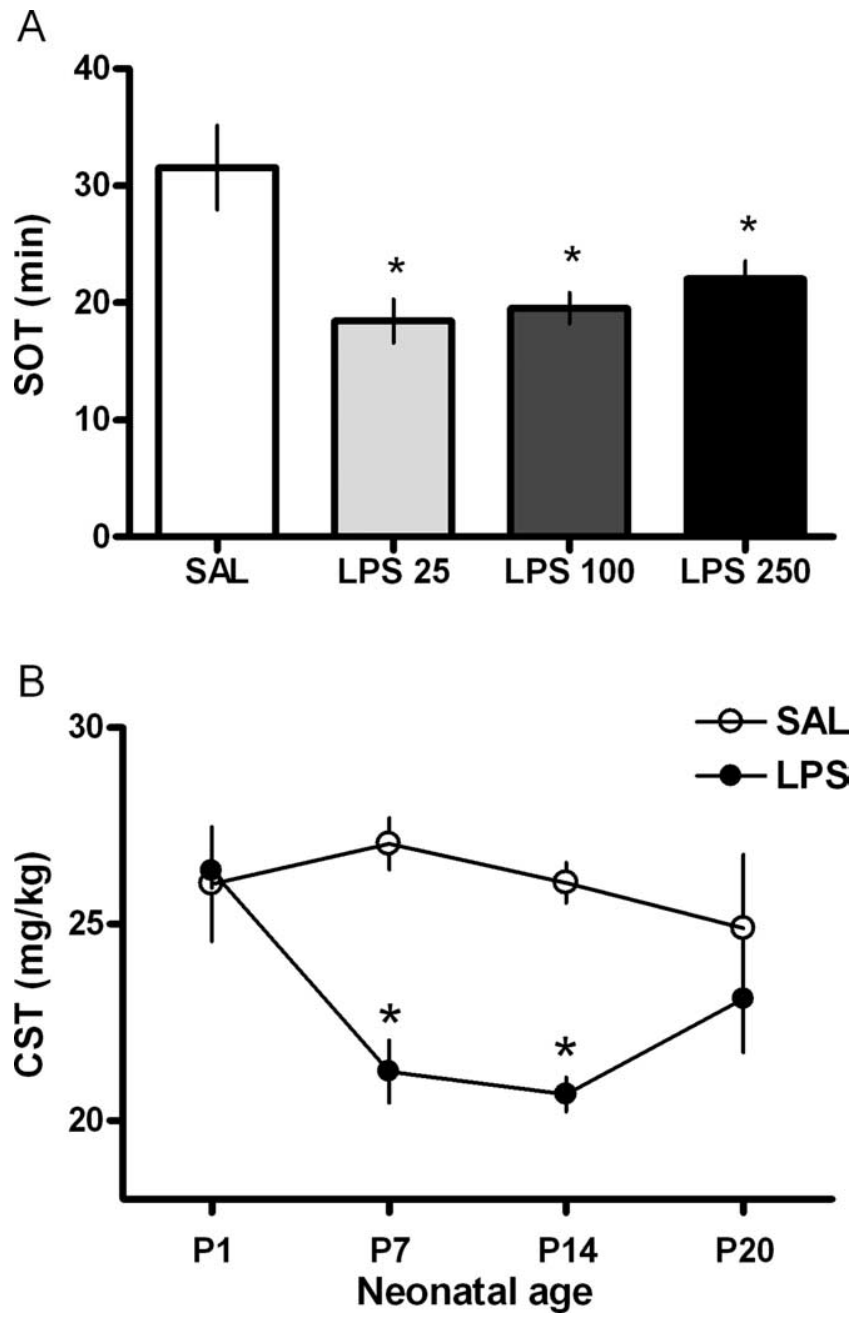

Figure 2. Adult seizure susceptibility to LI-PILO and PTZ after postnatal treatments of either SAL or LPS. $\boldsymbol{A}$, Latency in minutes to SOT in adult male rats that received LI-PIL0 after a P14 injection of either SAL ( $n=6)$, or LPS at 25,100 , or $250 \mu \mathrm{g} / \mathrm{kg}(n=4-5 / \mathrm{group})$. All rats that received LPS regardless of the dosage showed significantly $(p<0.05)$ faster SOTs compared with controls. Error bars indicate SEM. $\boldsymbol{B}$, Adult seizure susceptibility to PTZ after postnatal treatments of either SAL or LPS (100 $\mu \mathrm{g} / \mathrm{kg}$ ) on either P1, P7, P14, or P20 ( $n=5-6 /$ group). Data are presented as means \pm SEM for PTZ-induced clonic seizure threshold (CST) in mg/kg. Rats that received LPS on P7 and P14, but not on P1 or P20, showed significantly $(p<0.05)$ lower CSTs compared with controls. An asterisk denotes LPS-treated groups that differ significantly $(p<0.05)$ from controls.

0.01]. A similar increase in seizure susceptibility was seen after postnatal LPS at either 25, 100 (replicate), or $250 \mu \mathrm{g} / \mathrm{kg}$. A oneway ANOVA determined a significant difference between the postnatal treatments (three dosages of LPS and saline) and SOT $\left(F_{(3,19)}=5.97 ; p<0.01\right)$. Post hoc analysis showed that the mean SOTs of all P14 LPS-treated groups differed significantly from controls, but did not differ significantly from each other (Fig. 2A).

\section{LPS increases adult seizure susceptibility to PTZ during a critical postnatal period}

To examine the critical developmental period during which LPS could alter seizure susceptibility, we determined the clonic seizure threshold to PTZ for rats treated at P1, P7, P14, and P20, with either saline or LPS (Fig. 2 B). Both P7 and P14 LPS-treated rats showed seizure thresholds that were significantly lower than their respective controls $(t=5.65, p<0.01 ; t=7.79, p<0.01)$. 
In other words, they required less PTZ to induce generalized clonus. However, P1 and P20 LPS-treated rats showed no differences in seizure susceptibility compared with saline-treated controls.

\section{Increased seizure susceptibility,} cytokine expression, and neuronal degeneration after KA-induced seizures in LPS-treated rats

To determine whether postnatal LPS altered sensitivity to a different convulsant, we examined SOT in response to KA. Postnatal treatment $(\mathrm{P} 14)$ with LPS resulted in $\sim 30 \%$ faster mean SOT $(t=2.28$; $p<$ $0.05)$ compared with controls (Fig. 3A). We also observed an interaction between postnatal treatment and cytokine levels in the hippocampus after KA treatment. Adult rats that received LPS at P14 showed significantly more IL- $1 \beta(t=2.21 ; p<$ $0.05)$ and a trend toward increased TNF $\alpha$ $(t=1.72 ; p=0.1)$ levels $6 \mathrm{~h}$ after seizure (Fig. $3 B$ ). There was no interaction between postnatal treatment and microglia number or percentage of activated microglia $6 \mathrm{~h}$ after seizure (data not shown). In a subset of animals chosen for Fluoro-Jade histochemistry (to evaluate the effects on neuronal injury), there was a statistically significant difference between the saline and LPS-treated rats with respect to the number of degenerating neurons within the CA3 $(t=7.61 ; p<$ $0.01)$ and the CA1 region $(t=3.28 ; p<0.05)$ of the hippocampus, but not in the DG. The postnatal LPS-treated rats showed greater numbers of degenerating neurons, despite similar seizure durations than controls $24 \mathrm{~h}$ after KA seizure onset (Fig. 3C,D).

\section{TNF $\alpha$ mediates the long-term effect of LPS on adult} seizure susceptibility

To determine whether the neural proinflammatory cytokines TNF $\alpha$ or IL- $1 \beta$ were involved in the LPS-induced reduction in seizure threshold, P14 rats were given a single intracerebroventricular dose of IL-1ra or TNF $\alpha$ antibody at the same time as peripheral saline or LPS in an attempt to prevent the LPSinduced reduction in seizure threshold. We found that postnatal treatment with IL-1ra $(10 \mu \mathrm{g} / 5 \mu \mathrm{l})$ plus LPS did not block the significant reduction in adult seizure thresholds to PTZ (in milligrams per kilogram) compared with those displayed by postnatal saline-treated rats given the IL-1 ra [SAL plus IL-1ra ( $\mathrm{M}, 31.54$; SEM, 0.70); LPS plus IL-1 ra (M, 21.36; SEM, 1.54); $t=4.78 ; p<$ $0.01]$. In an additional series of experiments, the dose of IL-1 ra was increased to $50 \mu \mathrm{g} / 5 \mu \mathrm{l}$ and this also did not reverse the reduced seizure threshold [LPS plus SAL ( , 25.18; SEM, 2.36); LPS plus IL-1ra (M, 25.94; SEM, 1.54); $t<1 ; p>0.05$ ]. In contrast, the TNF $\alpha$ antibody blocked the LPS-induced change in seizure threshold (Fig. 4), because this group did not differ from controls $(t<1 ; p>0.05)$ given saline plus TNF $\alpha$ antibody at $\mathrm{P} 14$. Thus, TNF $\alpha$ antibody, but not IL-1ra, in the P14 rat blocked the reduction in adult seizure threshold brought about by LPS. When we injected the $\operatorname{rrTNF} \alpha$ (intracerebroventricularly) alone into P14 rats and induced seizures in adulthood, we found a significant $(t=2.52 ; p<0.05)$ reduction in seizure threshold to PTZ

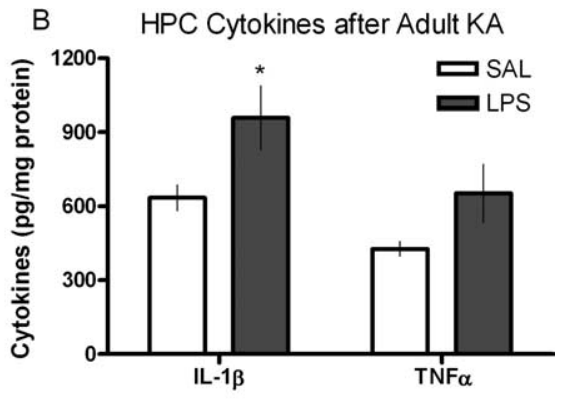

$\mathrm{D}$

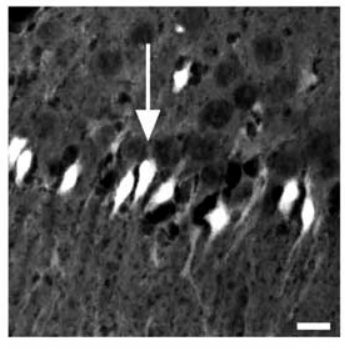

Figure 3. Adult seizure susceptibility to KA after postnatal treatments of either SAL or LPS (100 $\mu \mathrm{g} / \mathrm{kg})$. $A$, Latency in minutes Adult Seizure Suceptibility Following P14 ICV Treatments

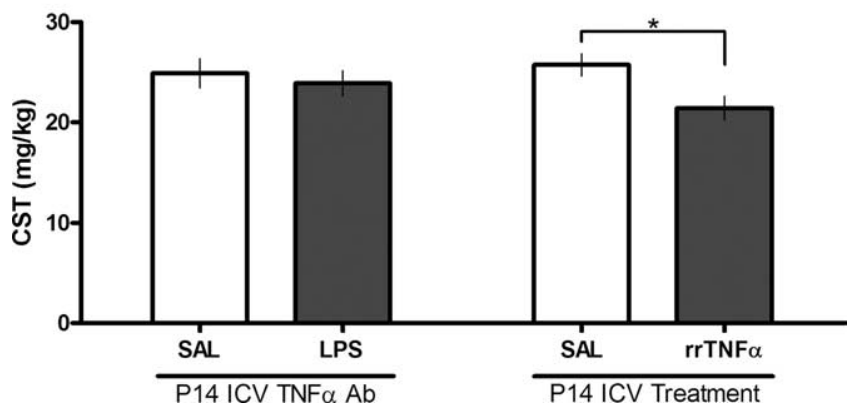

Figure 4. Adult seizure susceptibility to PTZ after P14 treatments of either SAL or LPS (100 $\mu \mathrm{g} / \mathrm{kg})$ and intracerebroventricular (ICV) injections of TNF $\alpha$ antibody (Ab) (50 $\mu \mathrm{g})(n=$ $9-11 /$ group) or intracerebroventricular injection of SAL or $\operatorname{rrTNF} \alpha(2 \mu \mathrm{g})(n=5-7 /$ group). Data are presented as means \pm SEMs for the clonic seizure threshold (CST) in milligrams per kilogram for adult rats that received PTZ. Rats that received LPS and the TNF $\alpha$ Ab showed no difference in CST compared with SAL controls suggesting that this drug was capable of blocking the LPS-induced facilitation of seizure susceptibility. Moreover, P14 intracerebroventricular $\operatorname{rrTNF} \alpha$ alone can reduce adult seizure threshold similar to LPS. The asterisk denotes that the $\operatorname{rrTNF} \alpha$-treated group differed significantly $(p<0.05)$ from controls.

when compared with P14 intracerebroventricular saline controls (Fig. 4). The intracerebroventricular treatment with $\operatorname{rrTNF} \alpha$ at P14 did not influence the gross development of the rats as inferred by their body weights that were not different from controls (data not shown).

Hippocampal cytokines and microglia are not chronically upregulated in LPS-treated rats

We examined cytokine levels (IL-1 $\beta$ and TNF $\alpha$ ) in the plasma (2 $\mathrm{h}$ after injection) and hippocampus ( 3 and $6 \mathrm{~h}$ after injection) of 

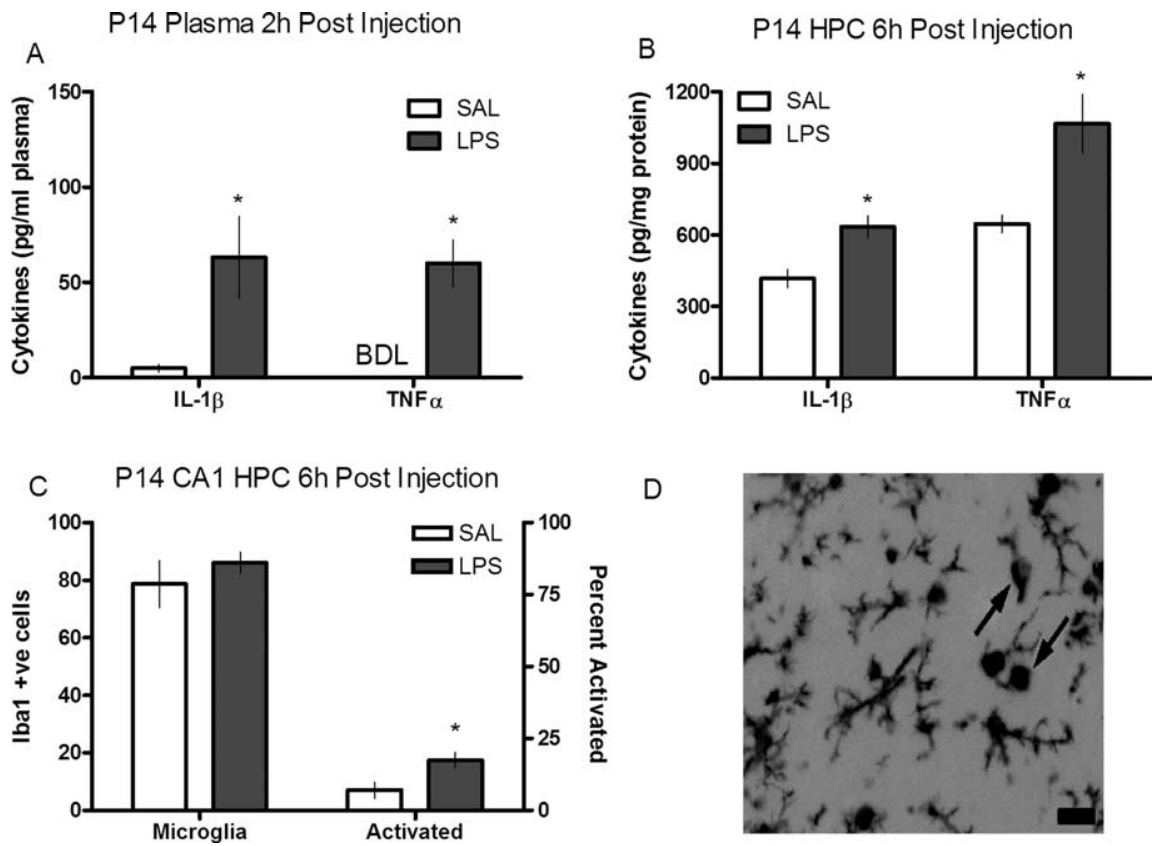

D

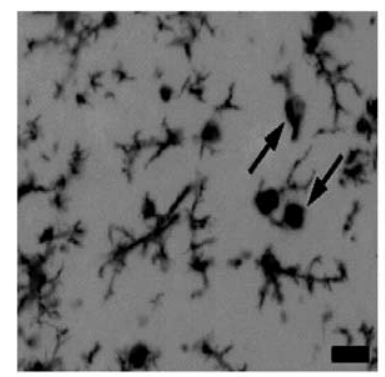

Figure 5. Acute cytokine (IL-1 $\beta$ and TNF $\alpha$ ) and microglia (Iba1 immunohistochemistry) data from P14 SAL- or LPS (100 $\mu \mathrm{g} / \mathrm{kg}$ )-treated rats ( $n=6 / \mathrm{group}$ ). $A$, IL-1 $\beta$ and TNF $\alpha$ concentrations in the plasma (in picograms per milliliter) of P14-treated rats $2 \mathrm{~h}$ after injection. Both cytokines are significantly $(p<0.05)$ increased in LPS-treated rats compared with controls. Values lower than the detection limit of the ELISA kit are labeled as below detectable levels (BDL). B, IL-1 $\beta$ and TNF $\alpha$ concentrations (in picograms per milligram of protein) in the hippocampus (HPC) of P14-treated rats $6 \mathrm{~h}$ after injection. Both cytokines are significantly $(p<0.05)$ increased in LPS-treated rats compared with controls. C, Total number of microglia (Iba1-positive) cells (left axis) and the percentage activated microglia count (right axis) of P14 SAL- or LPS-treated rats $6 \mathrm{~h}$ after injection. There is no difference in the number of Iba1-positive cells between LPS and control tissues; however, there are significantly $(p<0.05)$ greater numbers of activated microglia within the CA1 HPC of LPS-treated rats $6 \mathrm{~h}$ after injection. $D$, Photomicrograph of activated microglia cells (arrows) from the CA1 HPC of P14 LPS-treated rats. Scale bar, $20 \mu \mathrm{m}$. An asterisk denotes LPS-treated groups that differ significantly $(p<0.05)$ from controls. Error bars indicate SEM.

P14-treated rats to determine the amount of acute inflammation after LPS. We found a significant increase in both IL- $1 \beta(t=2.69$; $p<0.05)$ and TNF $\alpha(t=4.44 ; p<0.01)$ levels in the plasma $2 \mathrm{~h}$ after LPS administration (Fig. $5 A$ ). In the hippocampus, we found no significant difference in either cytokine at $3 \mathrm{~h}$ after LPS (data not shown); but at $6 \mathrm{~h}$ later, both IL-1 $\beta(t=3.42 ; p<0.05)$ and TNF $\alpha(t=2.82 ; p<0.05)$ were significantly increased in the hippocampus of LPS-treated rats compared with controls (Fig. $5 B$ ). In adult rats that received saline or LPS on P14, and no subsequent interventions, we observed no significant differences in either cytokine levels in the hippocampus (both values of $t<1$; $p>0.05$ ) (Fig. 6A).

Because microglia synthesize and release cytokines, we measured the total number of microglial cells (Ibal immunopositive) and the percentage of activated microglia within the CA1 hippocampus acutely $(6 \mathrm{~h})$ after LPS injection at P14, and in adult rats after P14 saline or LPS. Six hours after peripheral LPS administration to P14 rats, there were no significant $(t<1 ; p>0.05)$ differences in the total number of Iba1-positive cells within the CA1 hippocampus; however, the percentage of activated microglia was significantly $(t=2.64 ; p<0.05)$ increased in LPS-treated rats (Fig. $5 C, D$ ). In adults that received saline or LPS on P14, and no subsequent interventions, we observed no significant differences in either the number of microglia or the percentage of activated microglia (both values of $t<1 ; p>0.05$ ) between treatments (Fig. 6B).

To examine baseline astrocyte numbers, we immunostained adult hippocampal sections from rats treated at P14 with either saline or LPS. We found no difference between saline and LPS- treated rats in the number of GFAPpositive cells in the DG and CA3 regions of the hippocampus (Fig. 6C). However, there were significantly $(t=2.56 ; p<0.05)$ greater numbers of GFAP-positive cells counted in the CA1 region of the hippocampus of LPS-treated rats compared with controls (Fig. 6C,D). These cells appeared to be more hypertrophied with thickened processes in the LPS-treated group compared with controls.

\section{Discussion}

The most exciting finding of the present study is that a mild inflammatory response evoked by LPS during a critical period of development causes a long-lasting increase in hippocampal excitability in vitro, and enhanced seizure susceptibility to the convulsants LI-PILO, KA, and PTZ in vivo. The latter effect was observed over a range of mildly inflammatory doses of LPS and was only evident if administered during the second postnatal week (P7 and P14), and not before (P1) or after (P20) this time. Importantly, inactivation of the proinflammatory cytokine TNF $\alpha$ with an intracerebroventricular $\mathrm{TNF} \alpha$ antibody blocked the long-term changes to seizure susceptibility induced by LPS, whereas intracerebroventricular administration of $\operatorname{rrTNF} \alpha$ alone mimicked the effect of LPS on seizure susceptibility. These novel results indicate that a single transient inflammatory episode during development can modify the brain through a TNF $\alpha$-dependant mechanism, making it more susceptible to generate seizures in adulthood.

There was some concern that the increased susceptibility to convulsant drugs might be attributable to changes in the access of these convulsants into the brain. For example, LPS can acutely alter blood-brain barrier permeability (Mayhan, 1998), and it is possible that such a change in the developing rat may be permanent. Other possibilities include LPS-induced alterations in hepatic enzymes (Agrawal and Shapiro, 2005) that result in reduced peripheral metabolism and therefore higher effective concentrations of the convulsants. There is also evidence that postnatal LPS increases hypothalamic-pituitary-adrenal axis and corticosterone reactivity (Ellis et al., 2005), which in turn may promote seizure activity (Roberts and Keith, 1995; Baram and Hatalski, 1998). However, the fact that the hippocampus of LPS-treated rats displayed increased excitability in vitro argues against these possibilities and suggests that enduring changes in the structural or functional properties of the brain may occur after selective postnatal treatment with LPS.

Possible mechanisms leading to increased neuronal excitability are so numerous that their elucidation is beyond the scope of this study. However, the fact that the fEPSP is increased makes the Schaffer collateral-CA1 pyramidal cell synapse one possible target. This is an AMPA-mediated potential that can be modified through alterations in presynaptic function, leading to increased transmitter release or alterations in the transduction mechanisms of postsynaptic receptors (Bredt and Nicoll, 2003). For example, hyperthermia-induced seizures in postnatal rats cause a decrease 

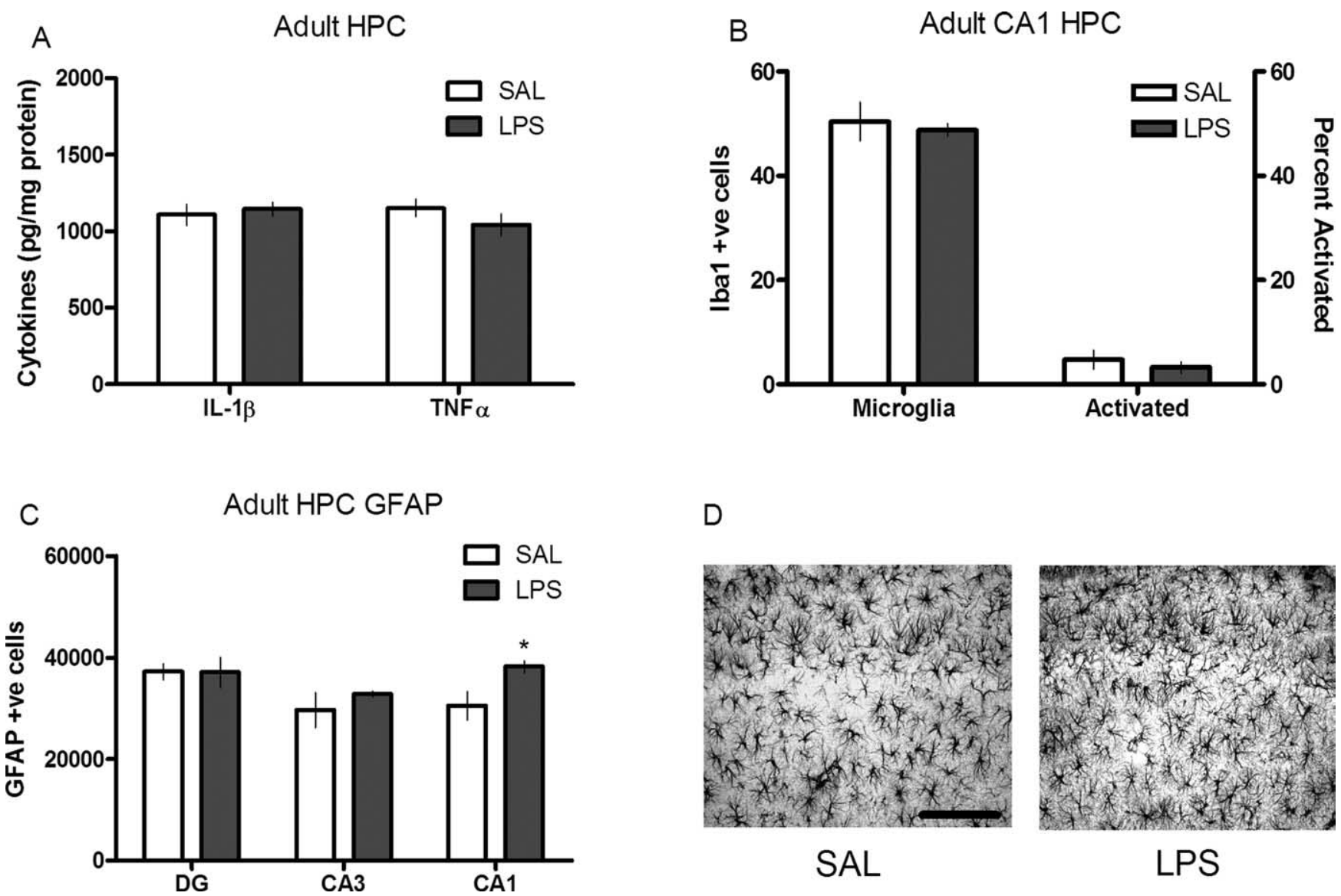

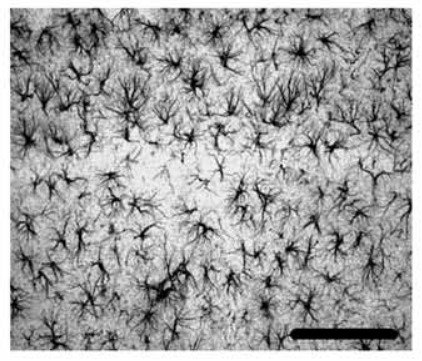

SAL

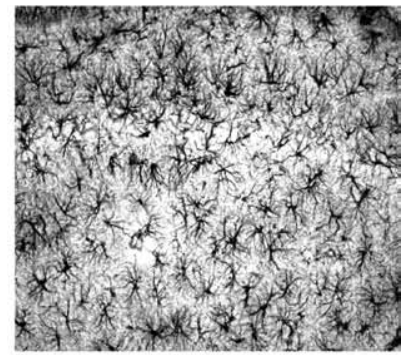

LPS

Figure 6. Adult cytokine (IL-1 $\beta$ and TNF $\alpha$ ), microglia (Iba1), and GFAP immunohistochemistry data from rats treated with SAL or LPS (100 $\mu \mathrm{g} / \mathrm{kg})$ on P14 ( $n=4-6 / \mathrm{group})$. $A$, IL-1 $\beta$ and TNF $\alpha$ concentrations in adult hippocampus (HPC) of rats treated at P14 with either SAL or LPS. Both cytokines are not significantly different between SAL- and LPS-treated groups. B, Total number of microglia (Iba1-positive) cells (left axis) and the percentage activated microglia count (right axis) of adult rats treated at P14 with SAL or LPS. There is no difference in the number of Iba1-positive cells or percentage activated between LPS and control tissues. C, Total number of GFAP-immunopositive cells within the DG, CA3, and CA1 regions of the HPC of adult animals treated at P14 with either SAL or LPS. There was a significant $(p<0.05)$ increase in the number of GFAP-positive cells in the CA1 HPC of rats treated at P14 with LPS compared with controls. $D$, Photomicrographs of GFAP-positive cells in the CA1 HPC of adult SAL- and LPS-treated rats. Scale bar, $150 \mu \mathrm{m}$. An asterisk denotes LPS-treated groups that differ significantly $(p<0.05)$ from controls. Error bars indicate SEM.

in $\mathrm{GABA}_{\mathrm{B}}$-mediated inhibition at the Schaffer collateral synapse (Leung and $\mathrm{Wu}, 2006$ ). Alternatively, changes in intrinsic membrane excitability, such as through modification of hyperpolarization activated current channels, could be equally altered as suggested by other postnatal interventions (Brewster et al., 2002).

We were surprised that our data resulting from intracerebroventricular injection of the IL-1ra did not reveal a role for IL- $1 \beta$ in the long-term effect of LPS on seizure thresholds. IL- $1 \beta$ is released in the hippocampus in a similar manner to TNF $\alpha$ after peripheral LPS treatment (Fig. $5 B$ ) and is known to have acute effects on neuronal excitability and excitotoxicity leading to seizure development (Heida et al., 2005; Vezzani and Baram, 2007). However, our data implicating $\mathrm{TNF} \alpha$ in the programming response of LPS point to other potential causative mechanisms. TNF $\alpha$ can independently enhance excitatory synaptic strength by increasing membrane insertion of AMPA receptors in cultured hippocampal pyramidal neurons (Beattie et al., 2002; Stellwagen et al., 2005), and reduce the overall inhibitory currents mediated through $\mathrm{GABA}_{\mathrm{A}}$ receptors in vitro (Wang et al., 2000; Stellwagen et al., 2005). TNF $\alpha$ is significantly increased in the blood and brain (hippocampus) after a peripheral LPS injection at P14. Because our data with the TNF $\alpha$ antibody and recombinant agonist preparations imply that TNF $\alpha$ is necessary and sufficient to program the long-term changes in neuronal excitability, we suggest that TNF $\alpha$-induced changes, such as those described above, may be permanent when established during a vulnerable developmental period.

We showed that the LPS-precipitated changes to adult seizure susceptibility are linked to a critical developmental period (P7 and P14). This time window is similar to the period we previously observed for other physiological changes caused by postnatal LPS (Spencer et al., 2006b). Interestingly, this is also the time when long-term potentiation-induced plasticity first becomes apparent (e.g., P7) and shows maximum responsivity (e.g., P15) (Harris and Teyler, 1984). Thus, we may suspect that some permanent change has taken place during this relatively sensitive period of development in which the effects of LPS (and TNF $\alpha$ ) can modify synapses. Alternatively, TNF $\alpha$ is known to be essential in the normal development of the hippocampus through regulation of neurotrophic factors such as nerve growth factor and brainderived neurotrophic factor (Golan et al., 2004). The possibility exists that "optimal" levels of TNF $\alpha$ may be perturbed after LPSinduced inflammation, even at potentially low doses (Fig. 2A). Future studies will be needed to address the potential mechanisms through which postnatal TNF $\alpha$ permanently alters neuronal function to enhance excitability and seizure propensity.

Although cytokines and microglia were not chronically perturbed in the LPS-treated rats, immunostaining for GFAP indi- 
cated greater numbers of astrocytes within the CA1 hippocampus of rats given LPS. In other words, LPS administration at P14 resulted in a chronic, although mild form of astrogliosis, a feature commonly found in patients with mesial temporal lobe epilepsy (Eid et al., 2008). Other reports have also implicated increased astrocyte numbers and distributions to a heightened susceptibility to seizures in a number of seizure models (Somera-Molina et al., 2007; Oberheim et al., 2008). Like microglia, astrocytes can also synthesize and release proinflammatory cytokines (Dong and Benveniste, 2001; Kipp et al., 2008; Vezzani et al., 2008; Wetherington et al., 2008). It is possible that they may contribute to the reduced seizure thresholds and other pathological sequelae in the adult brain, but it remains to be determined how LPS (and possibly TNF $\alpha$ ) might induce long-lasting changes in astrocytic number, morphology, or function.

Our results show that when postnatal LPS-treated rats were subjected to KA as adults, they displayed greater cytokine production (IL-1 $\beta$ in particular) and greater neuronal injury in the CA 3 and CA1 hippocampus, regions that are typically affected by KA seizures (Ben Ari, 1985; Silveira et al., 2002). In keeping with the argument that cytokines (primarily IL-1 $\beta$ ) are central to enhanced seizure susceptibility (Vezzani and Baram, 2007), other work has identified proinflammatory cytokines as mediators of CNS injury (Allan and Rothwell, 2001; Allan et al., 2005; Sherwin and Fern, 2005), possibly via facilitation of apoptotic processes in the brain (Thornton et al., 2006). Because our observed increases in IL- $1 \beta$ appear at $6 \mathrm{~h}$ after seizure onset, this could easily account for the greater neuronal injury (as inferred by Fluoro-Jade histochemistry) in the KA-treated rats seen the next day, because proinflammatory cytokines can exacerbate excitotoxic insults (Bernardino et al., 2008; Vezzani et al., 2008). In addition, as both our current data and previous experiments suggest (Bilbo et al., $2005)$, IL- $1 \beta$ can be specifically primed to generate a more robust response in adulthood by exposure to inflammation during development. Such priming may explain why we did not observe an abrupt increase in microglial activation, but recorded pronounced cytokine levels after KA seizures (Fig. 3B). One possibility is that the increased proliferation of hippocampal CA1 astrocytes induced by LPS [an effect potentially mediated by TNF $\alpha$ (Barna et al., 1990)] may be important in providing the IL-1 $\beta$ responsible in facilitating seizure onset and the magnitude of neuronal injury after seizure.

Clinically, CNS infections occur with some frequency in young children and may be associated with an increased risk for late unprovoked seizures (Rantakallio et al., 1986; Herman, 2002). In those patients surviving CNS infections, the risk for epilepsy was highest during the first 5 years after infection and remained elevated for the next 15 years (Annegers et al., 1988). Currently, there is limited clinical evidence to suggest that peripheral childhood infection contributes to the etiology of adult epilepsies. However, based on the novel data presented here, relatively mild early-life inflammation may be associated with permanent modifications in seizure susceptibility that persist well into adulthood. This may warrant additional patient history review to ascertain whether such a relationship exists. Our data raise the possibility that the known differences in adult seizure susceptibility to very similar insults may have their etiology in a common postnatal infection.

\section{References}

Agrawal AK, Shapiro BH (2005) Neonatal phenobarbital imprints overexpression of cytochromes $\mathrm{P} 450$ with associated increase in tumorigenesis and reduced life span. FASEB J 19:470-472.
Allan SM, Rothwell NJ (2001) Cytokines and acute neurodegeneration. Nat Rev Neurosci 2:734-744.

Allan SM, Tyrrell PJ, Rothwell NJ (2005) Interleukin-1 and neuronal injury. Nat Rev Immunol 5:629-640.

Annegers JF, Hauser WA, Beghi E, Nicolosi A, Kurland LT (1988) The risk of unprovoked seizures after encephalitis and meningitis. Neurology 38:1407-1410.

Avishai-Eliner S, Brunson KL, Sandman CA, Baram TZ (2002) Stressedout, or in (utero)? Trends Neurosci 25:518-524.

Baram TZ, Hatalski CG (1998) Neuropeptide-mediated excitability: a key triggering mechanism for seizure generation in the developing brain. Trends Neurosci 21:471-476.

Barna BP, Estes ML, Jacobs BS, Hudson S, Ransohoff RM (1990) Human astrocytes proliferate in response to tumor necrosis factor alpha. J Neuroimmunol 30:239-243.

Bartfai T, Sanchez-Alavez M, Andell-Jonsson S, Schultzberg M, Vezzani A, Danielsson E, Conti B (2007) Interleukin-1 system in CNS stress: seizures, fever, and neurotrauma. Ann N Y Acad Sci 1113:173-177.

Beattie EC, Stellwagen D, Morishita W, Bresnahan JC, Ha BK, Von Zastrow M, Beattie MS, Malenka RC (2002) Control of synaptic strength by glial TNFalpha. Science 295:2282-2285.

Ben-Ari Y (1985) Limbic seizure and brain damage produced by kainic acid: mechanisms and relevance to human temporal lobe epilepsy. Neuroscience 14:375-403.

Bernardino L, Balosso S, Ravizza T, Marchi N, Ku G, Randle JC, Malva JO, Vezzani A (2008) Inflammatory events in hippocampal slice cultures prime neuronal susceptibility to excitotoxic injury: a crucial role of P2X(7) receptor-mediated IL-1beta release. J Neurochem, in press.

Bilbo SD, Levkoff LH, Mahoney JH, Watkins LR, Rudy JW, Maier SF (2005) Neonatal infection induces memory impairments following an immune challenge in adulthood. Behav Neurosci 119:293-301.

Boissé L, Mouihate A, Ellis S, Pittman QJ (2004) Long-term alterations in neuroimmune responses after neonatal exposure to lipopolysaccharide. J Neurosci 24:4928-4934.

Boissé L, Spencer SJ, Mouihate A, Vergnolle N, Pittman QJ (2005) Neonatal immune challenge alters nociception in the adult rat. Pain 119:133-141.

Bredt DS, Nicoll RA (2003) AMPA receptor trafficking at excitatory synapses. Neuron 40:361-379.

Brewster A, Bender RA, Chen Y, Dube C, Eghbal-Ahmadi M, Baram TZ (2002) Developmental febrile seizures modulate hippocampal gene expression of hyperpolarization-activated channels in an isoform- and cellspecific manner. J Neurosci 22:4591-4599.

Cavalheiro EA, Silva DF, Turski WA, Calderazzo-Filho LS, Bortolotto ZA, Turski L (1987) The susceptibility of rats to pilocarpine-induced seizures is age-dependent. Brain Res 465:43-58.

De Simoni MG, Perego C, Ravizza T, Moneta D, Conti M, Marchesi F, De Luigi A, Garattini S, Vezzani A (2000) Inflammatory cytokines and related genes are induced in the rat hippocampus by limbic status epilepticus. Eur J Neurosci 12:2623-2633.

Dong Y, Benveniste EN (2001) Immune function of astrocytes. Glia 36:180-190.

Dubé C, Vezzani A, Behrens M, Bartfai T, Baram TZ (2005) Interleukin1beta contributes to the generation of experimental febrile seizures. Ann Neurol 57:152-155.

Dubé C, Richichi C, Bender RA, Chung G, Litt B, Baram TZ (2006) Temporal lobe epilepsy after experimental prolonged febrile seizures: prospective analysis. Brain 129:911-922.

Eid T, Williamson A, Lee TS, PetroffOA, de Lanerolle NC (2008) Glutamate and astrocytes-key players in human mesial temporal lobe epilepsy? Epilepsia 49 [Suppl 2]:42-52.

Eklind S, Mallard C, Arvidsson P, Hagberg H (2005) Lipopolysaccharide induces both a primary and a secondary phase of sensitization in the developing rat brain. Pediatr Res 58:112-116.

Ellis S, Mouihate A, Pittman QJ (2005) Early life immune challenge alters innate immune responses to lipopolysaccharide: implications for host defense as adults. FASEB J 19:1519-1521.

Ellis S, Mouihate A, Pittman QJ (2006) Neonatal programming of the rat neuroimmune response: stimulus specific changes elicited by bacterial and viral mimetics. J Physiol 571:695-701.

Fujikawa DG, Shinmei SS, Cai B (2000) Kainic acid-induced seizures produce necrotic, not apoptotic, neurons with internucleosomal DNA cleav- 
age: implications for programmed cell death mechanisms. Neuroscience 98:41-53.

Galic MA, Persinger MA (2005) Sucrose ingestion decreases seizure onset time in female rats treated with lithium and pilocarpine. Epilepsy Behav 6:552-555.

Godbout JP, Johnson RW (2006) Age and neuroinflammation: a lifetime of psychoneuroimmune consequences. Neurol Clin 24:521-538.

Golan H, Levav T, Mendelsohn A, Huleihel M (2004) Involvement of tumor necrosis factor alpha in hippocampal development and function. Cereb Cortex 14:97-105.

Gottlieb A, Keydar I, Epstein HT (1977) Rodent brain growth stages: an analytical review. Biol Neonate 32:166-176.

Grady MS, Charleston JS, Maris D, Witgen BM, Lifshitz J (2003) Neuronal and glial cell number in the hippocampus after experimental traumatic brain injury: analysis by stereological estimation. J Neurotrauma 20:929-941.

Haas KZ, Sperber EF, Moshé SL, Stanton PK (1996) Kainic acid-induced seizures enhance dentate gyrus inhibition by downregulation of $\mathrm{GABA}_{\mathrm{B}}$ receptors. J Neurosci 16:4250-4260.

Hagberg H, Mallard C (2005) Effect of inflammation on central nervous system development and vulnerability. Curr Opin Neurol 18:117-123.

Harré EM, Galic MA, Mouihate A, Noorbakhsh F, Pittman QJ (2008) Neonatal inflammation produces selective behavioural deficits and alters $N$-methyl-D-aspartate receptor subunit mRNA in the adult rat brain. Eur J Neurosci 27:644-653.

Harris KM, Teyler TJ (1984) Developmental onset of long-term potentiation in area CA1 of the rat hippocampus. J Physiol 346:27-48.

Heida JG, Pittman QJ (2005) Causal links between brain cytokines and experimental febrile convulsions in the rat. Epilepsia 46:1906-1913.

Heida JG, Boissé L, Pittman QJ (2004) Lipopolysaccharide-induced febrile convulsions in the rat: short-term sequelae. Epilepsia 45:1317-1329.

Heida JG, Teskey GC, Pittman QJ (2005) Febrile convulsions induced by the combination of lipopolysaccharide and low-dose kainic acid enhance seizure susceptibility, not epileptogenesis, in rats. Epilepsia 46:1898-1905.

Herman ST (2002) Epilepsy after brain insult: targeting epileptogenesis. Neurology 59:S21-S26.

Ignatowski TA, Covey WC, Knight PR, Severin CM, Nickola TJ, Spengler RN (1999) Brain-derived TNFalpha mediates neuropathic pain. Brain Res 841:70-77.

Kent S, Bluthe RM, Dantzer R, Hardwick AJ, Kelley KW, Rothwell NJ, Vannice JL (1992) Different receptor mechanisms mediate the pyrogenic and behavioral effects of interleukin 1. Proc Natl Acad Sci USA 89:9117-9120.

Kipp M, Norkute A, Johann S, Lorenz L, Braun A, Hieble A, Gingele S, Pott F, Richter J, Beyer C (2008) Brain-region-specific astroglial responses in vitro after LPS exposure. J Mol Neurosci 35:235-243.

Layé S, Parnet P, Goujon E, Dantzer R (1994) Peripheral administration of lipopolysaccharide induces the expression of cytokine transcripts in the brain and pituitary of mice. Brain Res Mol Brain Res 27:157-162.

Leung LS, Wu K (2006) Epilepsy-based changes in hippocampal excitability: causes and effects. Adv Neurol 97:63-68.

Lian XY, Khan FA, Stringer JL (2007) Fructose-1,6-bisphosphate has anticonvulsant activity in models of acute seizures in adult rats. J Neurosci 27:12007-12011.

Long JM, Kalehua AN, Muth NJ, Calhoun ME, Jucker M, Hengemihle JM, Ingram DK, Mouton PR (1998) Stereological analysis of astrocyte and microglia in aging mouse hippocampus. Neurobiol Aging 19:497-503.

Mandhane SN, Aavula K, Rajamannar T (2007) Timed pentylenetetrazol infusion test: a comparative analysis with s.c.PTZ and MES models of anticonvulsant screening in mice. Seizure 16:636-644.

Mayhan WG (1998) Effect of lipopolysaccharide on the permeability and reactivity of the cerebral microcirculation: role of inducible nitric oxide synthase. Brain Res 792:353-357.

Meaney MJ, Szyf M (2005) Maternal care as a model for experiencedependent chromatin plasticity? Trends Neurosci 28:456-463.

Mehler MF, Kessler JA (1998) Cytokines in brain development and function. Adv Protein Chem 52:223-251.

Merrill JE (1992) Tumor necrosis factor alpha, interleukin 1 and related cytokines in brain development: normal and pathological. Dev Neurosci 14:1-10.

Motamedi GK, Salazar P, Smith EL, Lesser RP, Webber WR, Ortinski PI, Vicini S, Rogawski MA (2006) Termination of epileptiform activity by cooling in rat hippocampal slice epilepsy models. Epilepsy Res 70:200-210.

Nguyen KT, Deak T, Owens SM, Kohno T, Fleshner M, Watkins LR, Maier SF (1998) Exposure to acute stress induces brain interleukin-1beta protein in the rat. J Neurosci 18:2239-2246.

Oberheim NA, Tian GF, Han X, Peng W, Takano T, Ransom B, Nedergaard M (2008) Loss of astrocytic domain organization in the epileptic brain. J Neurosci 28:3264-3276.

Oprica M, Spulber SD, Aronsson AF, Post C, Winblad B, Schultzberg M (2006) The influence of kainic acid on core temperature and cytokine levels in the brain. Cytokine 35:77-87.

Paxinos G, Watson C (1998) The rat brain in stereotaxic coordinates, Ed 4. San Diego: Academic.

Perreault P, Avoli M (1991) Physiology and pharmacology of epileptiform activity induced by 4 -aminopyridine in rat hippocampal slices. J Neurophysiol 65:771-785.

Ramzan IM, Levy G (1985) Kinetics of drug action in disease states. XIV. Effect of infusion rate on pentylenetetrazol concentrations in serum, brain and cerebrospinal fluid of rats at onset of convulsions. J Pharmacol Exp Ther 234:624-628.

Rantakallio P, Leskinen M, von Wendt L (1986) Incidence and prognosis of central nervous system infections in a birth cohort of 12,000 children. Scand J Infect Dis 18:287-294.

Ravizza T, Rizzi M, Perego C, Richichi C, Veliskova J, Moshe SL, De Simoni MG, Vezzani A (2005) Inflammatory response and glia activation in developing rat hippocampus after status epilepticus. Epilepsia 46 [Suppl 5]:113-117.

Ravizza T, Boer K, Redeker S, Spliet WG, van Rijen PC, Troost D, Vezzani A, Aronica E (2006) The IL-1beta system in epilepsy-associated malformations of cortical development. Neurobiol Dis 24:128-143.

Reynolds JL, Ignatowski TA, Sud R, Spengler RN (2004) Brain-derived tumor necrosis factor-alpha and its involvement in noradrenergic neuron functioning involved in the mechanism of action of an antidepressant. J Pharmacol Exp Ther 310:1216-1225.

Roberts AJ, Keith LD (1995) Corticosteroids enhance convulsion susceptibility via central mineralocorticoid receptors. Psychoneuroendocrinology 20:891-902.

Salazar P, Tapia R, Rogawski MA (2003) Effects of neurosteroids on epileptiform activity induced by picrotoxin and 4 -aminopyridine in the rat hippocampal slice. Epilepsy Res 55:71-82.

Schmued LC, Albertson C, Slikker W Jr (1997) Fluoro-Jade: a novel fluorochrome for the sensitive and reliable histochemical localization of neuronal degeneration. Brain Res 751:37-46.

Sherwin C, Fern R (2005) Acute lipopolysaccharide-mediated injury in neonatal white matter glia: role of TNF-alpha, IL-1beta, and calcium. J Immunol 175:155-161.

Silveira DC, Sogawa Y, Holmes GL (2002) The expression of Fos following kainic acid-induced seizures is age-dependent. Eur J Neurosci 15:329-344.

Somera-Molina KC, Robin B, Somera CA, Anderson C, Stine C, Koh S, Behanna HA, Van Eldik LJ, Watterson DM, Wainwright MS (2007) Glial activation links early-life seizures and long-term neurologic dysfunction: evidence using a small molecule inhibitor of proinflammatory cytokine upregulation. Epilepsia 48:1785-1800.

Spencer SJ, Auer RN, Pittman QJ (2006a) Rat neonatal immune challenge alters adult responses to cerebral ischaemia. J Cereb Blood Flow Metab 26:456-467.

Spencer SJ, Martin S, Mouihate A, Pittman QJ (2006b) Early-life immune challenge: defining a critical window for effects on adult responses to immune challenge. Neuropsychopharmacology 31:1910-1918.

Spencer SJ, Mouihate A, Pittman QJ (2007) Peripheral inflammation exacerbates damage after global ischemia independently of temperature and acute brain inflammation. Stroke 38:1570-1577.

Stellwagen D, Beattie EC, Seo JY, Malenka RC (2005) Differential regulation of AMPA receptor and GABA receptor trafficking by tumor necrosis factor- $\alpha$. J Neurosci 25:3219-3228.

Thornton P, Pinteaux E, Gibson RM, Allan SM, Rothwell NJ (2006) Interleukin-1-induced neurotoxicity is mediated by glia and requires caspase activation and free radical release. J Neurochem 98:258-266.

Turrin NP, Rivest S (2004) Innate immune reaction in response to seizures: implications for the neuropathology associated with epilepsy. Neurobiol Dis 16:321-334. 
Turrin NP, Gayle D, Ilyin SE, Flynn MC, Langhans W, Schwartz GJ, PlataSalamán CR (2001) Pro-inflammatory and anti-inflammatory cytokine mRNA induction in the periphery and brain following intraperitoneal administration of bacterial lipopolysaccharide. Brain Res Bull 54:443-453.

Turski L, Ikonomidou C, Turski WA, Bortolotto ZA, Cavalheiro EA (1989) Review: cholinergic mechanisms and epileptogenesis. The seizures induced by pilocarpine: a novel experimental model of intractable epilepsy. Synapse 3:154-171.

Verma S, Nakaoke R, Dohgu S, Banks WA (2006) Release of cytokines by brain endothelial cells: a polarized response to lipopolysaccharide. Brain Behav Immun 20:449-455.

Vezzani A, Baram TZ (2007) New roles for interleukin-1 beta in the mechanisms of epilepsy. Epilepsy Curr 7:45-50.

Vezzani A, Granata T (2005) Brain inflammation in epilepsy: experimental and clinical evidence. Epilepsia 46:1724-1743.

Vezzani A, Moneta D, Richichi C, Aliprandi M, Burrows SJ, Ravizza T, Perego C, De Simoni MG (2002) Functional role of inflammatory cytokines and antiinflammatory molecules in seizures and epileptogenesis. Epilepsia 43 [Suppl 5]:30-35.
Vezzani A, Ravizza T, Balosso S, Aronica E (2008) Glia as a source of cytokines: implications for neuronal excitability and survival. Epilepsia 49 [Suppl 2]:24-32.

Virta M, Hurme M, Helminen M (2002) Increased plasma levels of pro- and anti-inflammatory cytokines in patients with febrile seizures. Epilepsia 43:920-923.

Vitkovic L, Bockaert J, Jacque C (2000) “Inflammatory" cytokines: neuromodulators in normal brain? J Neurochem 74:457-471.

Wang S, Cheng Q, Malik S, Yang J (2000) Interleukin-1beta inhibits gamma-aminobutyric acid type A $(\mathrm{GABA}(\mathrm{A}))$ receptor current in cultured hippocampal neurons. J Pharmacol Exp Ther 292:497-504.

West MJ, Slomianka L, Gundersen HJ (1991) Unbiased stereological estimation of the total number of neurons in the subdivisions of the rat hippocampus using the optical fractionator. Anat Rec 231:482-497.

Wetherington J, Serrano G, Dingledine R (2008) Astrocytes in the epileptic brain. Neuron 58:168-178.

Yonekawa WD, Kapetanovic IM, Kupferberg HJ (1995) The effects of anticonvulsant agents on 4-aminopyridine induced epileptiform activity in rat hippocampus in vitro. Epilepsy Res 20:137-150. 